\title{
Quistes uretrales parameatales. 3 nuevos casos pediátricos y revisión de la literatura
}

\author{
García Serrado D, Domínguez Hinarejos C, Martínez Verdú M, Serrano Durbá A, \\ Estornell Moragues F, García Ibarra F.
}

Servicio de Urología Pediátrica. Hospital Universitario La Fe. Valencia.

Actas Urol Esp. 2007;31(1):61-63

\section{RESUMEN}

\section{QUISTES URETRALES PARAMEATALES. 3 NUEVOS CASOS PEDIÁTRICOS Y REVISIÓN DE LA LITERATURA}

Presentamos 3 nuevos casos de quistes uretrales parameatales en edad pediátrica. Se revisa la literatura y comentamos los hallazgos histológicos y el manejo ambulatorio de estos pacientes.

Palabras clave: Quiste. Uretra. Pediatría.

\section{ABSTRACT}

PARAMEATAL URETHRAL CYSTS. 3 NEW PAEDIATRIC CASES AND LITERATURE REVIEW

We present 3 new cases of urethral parameatal cysts in paediatric age. Literature is reviewed and histological data and ambulatory management are discussed.

Keywords: Cyst. Urethra. Pediatrics.

$\mathrm{L}$ os quistes parameatales uretrales son entidades raras, los diagnosticados en la edad pediátrica son menos del $50 \%{ }^{1,2}$. Actualmente se incluyen dentro del concepto de quistes del rafe medio del pene ${ }^{3}$. Se han denominado de múltiples formas: quistes uretroides, epidérmicos, mucoides, cistoadenomas mucinosos ${ }^{4}$.

$\mathrm{Su}$ incidencia es baja, aunque puede estar justificado que por su benignidad, ausencia de clínica y larga evolución estén infra diagnosticados.

Aunque en general se acepta su origen congénito y a pesar de haber más de 160 casos descritos $^{1,2,4}$ persiste la discusión sobre su formación ${ }^{4}$ dada la variabilidad en la edad de presentación y los infrecuentes casos referidos como secundarios.

El tratamiento pasa por la escisión completa del quiste para evitar su recidiva y complicaciones miccionales futuras.

\section{CASOS CLÍNICOS}

Desde marzo de 2001 a mayo 2005 se han atendido en consultas externas de urología pediátrica a tres pacientes que presentan quistes parameatales. La edad de presentación varía desde 3 años de edad a 7 años, con un tiempo de evolución de una semana a 2,5 años (Tabla 1). Los pacientes fueron traídos por aparición de una masa parauretral con molestias urinarias y alteración del chorro miccional. Se practicó escisión completa del quiste en los tres casos. En dos de ellos en la unidad de cirugía ambulatoria y el restante ingresó por practicarse intervención otorrinoralingológica en el mismo acto y requerir control postoperatorio de la misma.

El diagnóstico anátomo-patológico fue en dos casos de quistes, con epitelio cúbico en uno y queratinoso de tipo epidérmico en otro. El caso restante se informó de neoformación vascular compatible con hemangioma. 
Tabla 1

\begin{tabular}{ccccll}
\hline Caso & Edad & Tiempo evolución & Tamaño $(\mathbf{m m})$ & Intervención & Histologia \\
\hline 1 & 3 & 2,5 años & $23 \times 14$ & Quistectomía & Hemangioma \\
2 & 7 & 1 año & $4 \times 3$ & $\begin{array}{l}\text { Quistectomía }+ \\
\text { prepucioplastia }\end{array}$ & Quiste. Epitelio cúbico \\
3 & 3 & 1 semana & $20 \times 15$ & $\begin{array}{l}\text { Quistectomía }+ \\
\text { frenulo y prepucioplastia }\end{array}$ & Quiste. Epitelio epidérmico \\
\hline
\end{tabular}

La evolución ha sido satisfactoria con corrección estética completa y ausencia de complicaciones, sin estenosis meatal, ni alteraciones del flujo urinario con un seguimiento medio de 36 meses. (Figs. 1, 2 y 3).

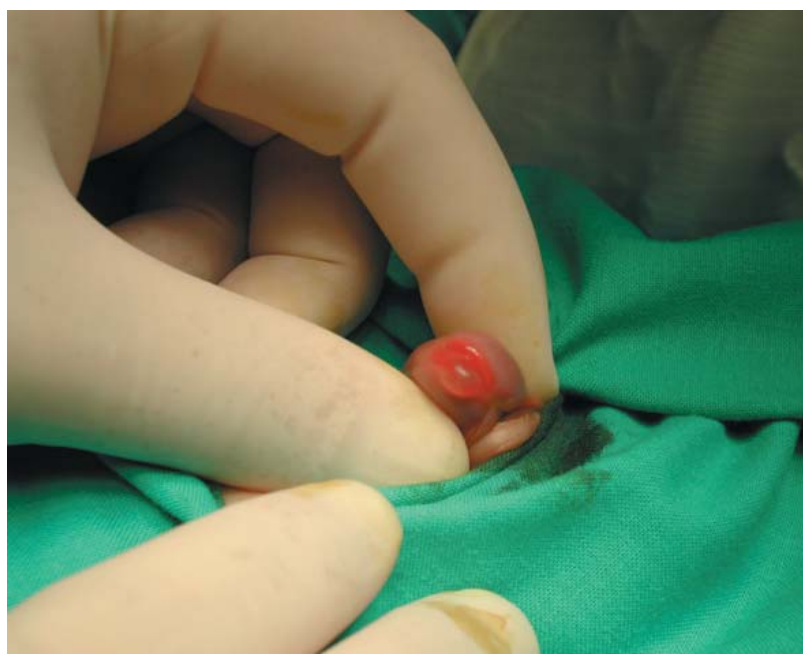

\section{FIGURA 1}

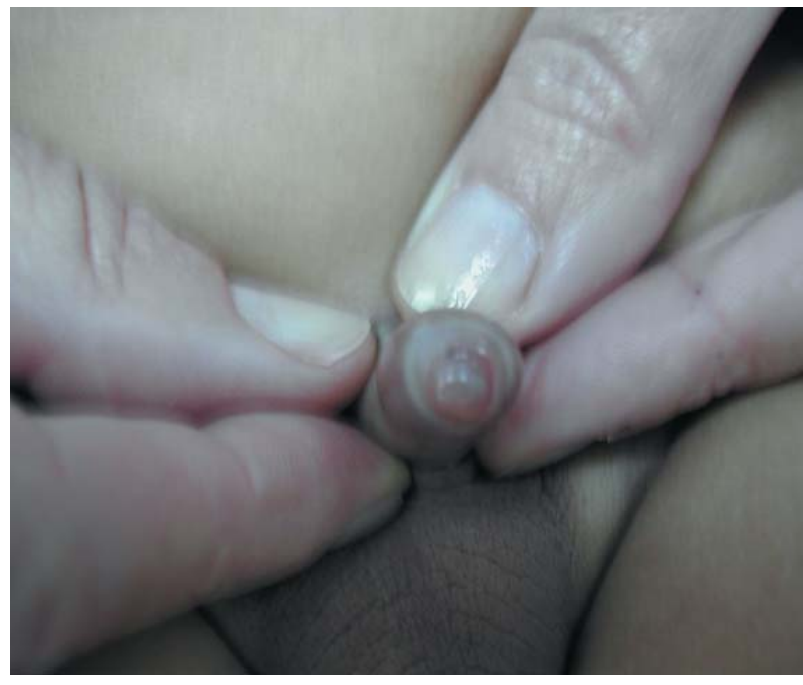

FIGURA 2

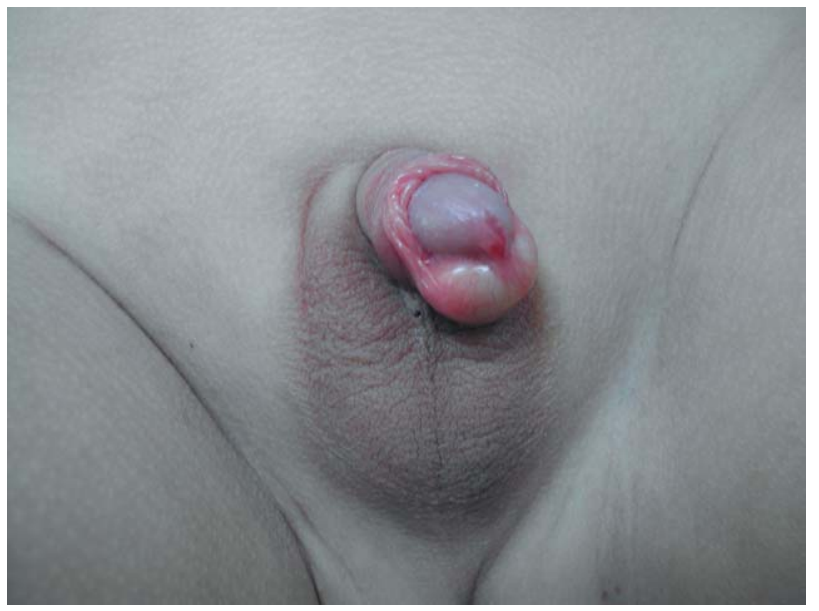

FIGURA 3

\section{DISCUSIŌN}

La aparición de masas quísticas a nivel para meatal no es una entidad frecuente, además las diversas revisiones que se han hecho previamente sobre el tema, no siempre coinciden en cuanto al número de casos descritos y año de la primera referencia ${ }^{1,4}$. Todo ello puede deberse a la confusión previa existente en la nomenclatura hasta su categorización como quistes del rafe medio del pene, que son los que abarcan los de localización parameática, del frenillo y del rafe medio peneano, escrotal y perineal. Todos éstos además se engloban en la categoría general de quistes genitales ${ }^{3}$.

Tampoco hay consenso en la literatura respecto a la etiología de los quistes parameatales ${ }^{2}$, se postula un origen congénito por fallo del proceso de delaminación y separación de la piel escrotal respecto a la glandar, por oclusión de los conductos parauretrales externos o adquirida, tras oclusión de estos ductos post traumatismo o infección aunque esto es más infrecuente y puede considerarse como anecdótico ${ }^{2,3}$. 
En nuestros casos dada la edad de los pacientes parece evidente que el origen es congénito, aunque el tiempo hasta la aparición o hasta que produce alteraciones macroscópicamente visibles es muy variable. Desde los 6 meses de vida a los 6 años, lo que concuerda con la gran disparidad reflejada en los artículos previos, que apuntan una edad media de presentación de 17,7 años ${ }^{2}$.

Habitualmente asintomáticos ${ }^{4}$ en 2 de nuestros casos los pacientes consultaron por molestias leves y alteraciones miccionales, destacando el caso número 1 en el que estando asintomático al diagnóstico y pese a recomendarse cirugía de entrada, los padres prefirieron actitud expectante durante 2 años y medio, siendo entonces necesaria la extirpación por las alteraciones del chorro urinario que producía.

La histología según se refleja en la literatu$\mathrm{ra}^{2,5}$, es en la mayoría de las ocasiones de tipo columnar; en nuestra serie, el primero de los casos presenta una histología compatible con hemangioma, que si bien no puede considerarse como un quiste propiamente dicho, su aspecto macroscópico era muy similar al resto de la iconografía hallada. Los otros dos presentaban uno un epitelio cuboidal y el otro queratinoso de tipo epidérmico, que coincide con el denominado escamoso en la literatura ${ }^{2}$.

La presencia de una formación hemangiomatosa en esta localización es excepcional, no encontrándose referencias en la bibliografía en varones y en edad pediátrica. Dentro de su rareza, la situación uretral motivando clínica diversa, es más frecuente, habiéndose propuesto múltiples tratamientos para su eliminación ${ }^{6-9}$.

Pese a su benignidad, es importante realizar la exéresis completa de los quistes al diagnóstico, ya que es la única forma de evitar las alteraciones del chorro miccional, molestias o traumatismos que puedan derivar de su crecimiento o recurrencia tras punción o marsupialización ${ }^{10}$. Merece la pena destacar que en ocasiones se encuentran varias formaciones quísticas con conexiones entre ellas por lo que es mandataria una cuidadosa disección y eliminación en bloque ${ }^{4}$.
Se ha recomendado la hospitalización de los pacientes pediátricos sometidos a este tipo de cirugía $^{1}$. Pensamos que no es necesario, sobre todo en los centros con Unidad de cirugía sin ingreso (UCSI) dado que las molestias miccionales son mínimas, menores que en una meatotomía, los cuidados postoperatorios son mínimos y la evolución posterior suele ser muy favorable cuando se realiza una técnica cuidadosa y se respeta el meato uretral.

\section{CONCLUSIONES}

Consideramos que el tratamiento debe ser al diagnóstico para evitar que con el paso del tiempo aumenten de volumen y provoquen alteraciones del chorro miccional, así como su ruptura lo que dificultaría la exéresis completa.

\section{REFERENCIAS}

1. Suarez Cuenca JA, Sanchez Garza M, Calderon Ferro F, Estrada Barbosa A. Quiste parameatal: presentación de dos casos y revisión de la literatura. Arch Esp Urol. 1998; 51(7):716-718.

2. Otsuka T, Ueda Y, Terauchi M, Kinoshita Y. Median raphe (parameatal) cysts of the penis. J Urol. 1998;159(6):19181920.

3. Asarch RG, Golitz LE, Sausker WF, Kreye GM. Median raphe cysts of the penis. Arch Dermatol. 1979;115(9): 1084-1086.

4. Koga S, Arakaki Y, Matsuoka M, Ohyama C. Parameatal urethral cysts of the glans penis. Br J Urol. 1990;65(1): 101-103.

5. Yoshida K, Nakame Y, Negishi T. Parameatal urethral cysts. Urology. 1985;26(5):490-491.

6. Roberts JW, Devine CJ Jr. Urethral hemangioma: treatment by total excision and grafting. J Urol. 1983;129(5): 1053-1054.

7. Khaitan A, Hemal AK. Urethral hemangioma: laser treatment. Int Urol Nephrol. 2000;32(2):285-286.

8. Parshad S, Yadav SP, Arora B. Urethral hemangioma. An unusual cause of hematuria. Urol Int. 2001;66(1):43-45.

9. Hammond L, Kamel OW, Ost L. Hemangioma associated with urethral stricture. J Urol. 2003;170(4 Pt 1):1309.

10. Oka M, Nakashima K, Sakoda R.Br Congenital parameatal urethral cyst in the male. J Urol. 1978;50(5):340-341.

Correspondencia autor: Dr. D. García Serrado. Servicio de Urologia Pediátrica. Hospital Infantil La Fe. Avda. Campanar, 21. 46009 Valencia. Tel.: 963862700

E-mail autor: diego.garcia@uv.es

Información artículo: Nota clínica

(Trabajo aceptado septiembre 2006) 